\title{
An EPR and DFT study on the primary radical formed in hydroxylation reactions of 2,6- dimethoxy-1,4-benzoquinone
}

\author{
Haleh H. Haeri, Ivan Bogeski, Rubin Gulaboski, Valentin Mirceski, Markus
} Hoth \& Reinhard Kappl

To cite this article: Haleh H. Haeri, Ivan Bogeski, Rubin Gulaboski, Valentin Mirceski, Markus Hoth \& Reinhard Kappl (2016): An EPR and DFT study on the primary radical formed in hydroxylation reactions of 2,6-dimethoxy-1,4-benzoquinone, Molecular Physics, DOI: 10.1080/00268976.2016.1158424

To link to this article: http://dx.doi.org/10.1080/00268976.2016.1158424

View supplementary material $₫$

Published online: 17 Mar 2016.

Submit your article to this journal $₫$

Q View related articles $₫$

View Crossmark data 


\title{
An EPR and DFT study on the primary radical formed in hydroxylation reactions of 2,6-dimethoxy-1,4-benzoquinone
}

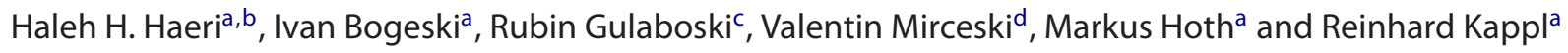 \\ ${ }^{a}$ Department of Biophysics, School of Medicine, Saarland University, Homburg, Germany; ${ }^{b}$ Department of Chemistry, Institute for Physical \\ Chemistry, Martin-Luther-University, Halle (Saale), Germany; ' ${ }^{\top}$ Faculty of Medical Sciences, Goce Delčev University, Stip, Republic of Macedonia; \\ dDepartment of Chemistry, Faculty of Natural Sciences and Mathematics, "Ss Cyril and Methodius" University, Skopje, Republic of Macedonia
}

\begin{abstract}
The quinone compound 2,6-dimethoxy-1,4-benzoquinone is hydroxylated in alkaline aqueous solution with $\mathrm{pH}$ above 12. Electron paramagnetic resonance experiments showed that two transient radicals are formed in this reaction. The radical appearing first is assigned to a one electron reduced 2,6-dimethoxy-1,4-benzoquinone, receiving the electron from an intermediate anionic hydroxylated species. For this primary radical, all proton couplings were determined (quinoid ring protons: $1.453 \mathrm{G}$, methyl protons: $0.795 \mathrm{G}$ ). The density functional theory method was applied to obtain electronic and structural information of the primary radical and a solution structure is suggested. For approaching the experimental hyperfine couplings in theoretical models, it was necessary to consider effects of external polarisation arising from water molecules near one carbonyl group, and the orientation of methoxy groups towards the quinone ring. With this approach, the secondary radical formed in the hydroxylation reaction, and the transient radicals found for other biologically important quinones (including coenzymes $\mathrm{Q}$ ) and their hydroxylated species may become accessible.
\end{abstract}
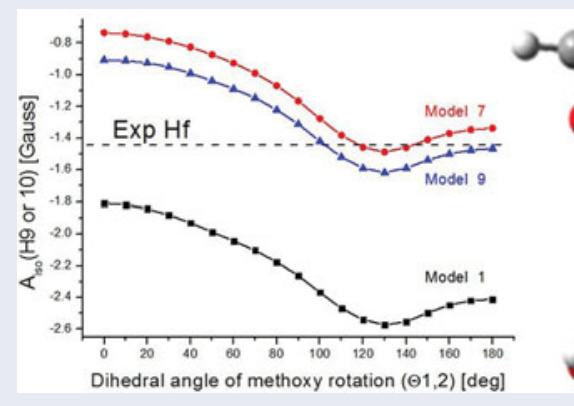

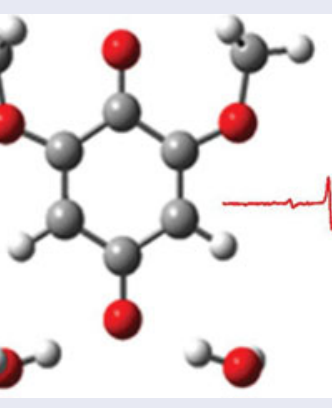

\section{ARTICLE HISTORY}

Received 8 January 2016

Accepted 17 February 2016

\section{KEYWORDS}

Methoxy benzoquinones; semi-quinone radical; density functional theory; reactive oxygen species; metal ligands

\section{Introduction}

Quinones have received great attention in chemistry because these compounds are involved in many fundamental processes ranging from simple organic reactions $[1,2]$ to industrially applied polymerisation reactions [36]. In addition, quinones are well known for their essential roles in biological systems, such as their involvement in the electron transport chain [7-10] and other reactions of enzymes or nucleic acids [11,12]. Recently, quinone-like compounds were recognised as calcium transporters across biomimetic membranes. Bennett et al. [13] demonstrated that synthetic 2-palmytoylhydroquinone (2PHQ) is capable to transfer calcium ions across a liposome bilayer in a redox dependent manner.
They found that only the reduced $2 \mathrm{PHQ}$ is binding the ions. In another study, Mirceski et al. [14] have shown mainly by voltammetric techniques that reduced $2 \mathrm{PHQ}$ can bind and transfer not only $\mathrm{Ca}^{2+}$, but also other divalent ions such as $\mathrm{Ba}^{2+}, \mathrm{Sr}^{2+}$ or $\mathrm{Mg}^{2+}$. Both studies revealed the crucial role of two adjacent oxygen atoms for providing a redox dependent complexation site. Such a structural configuration is not present in naturally occurring coenzymes like $\mathrm{Q}_{10}$ or the related compound $\mathrm{Q}_{1}$. Therefore, these quinones are not able to bind divalent ions in any redox state by a similar mechanism. However, we have recently shown that in alkaline aqueous solutions or upon action of cytochrome P450, hydroxylated derivatives of $\mathrm{Q}_{1}$ and $\mathrm{Q}_{10}$ are formed which bind

CONTACT Haleh H. Haeri haleh.hashemi-haeri@chemie.uni-halle.de; Reinhard Kappl reinhard.kappl@uks.eu (-) Supplemental data for this article can be accessed at: http://dx.doi.org/10.1080/00268976.2016.1158424 
calcium ions and transfer them across biomembranes, a feature of potential physiologic relevance [15]. In particular, for the alkaline medium, the involvement of intermediate quinone radicals was detected by electron paramagnetic resonance (EPR) experiments in the liquid phase. In this context, we addressed the possible mechanisms of the hydroxylation reaction by studying fully and partially substituted quinone compounds containing two methoxy groups. Because for non- or partially substituted quinones, the hydroxylation mechanism is much better understood $[16,17]$ as compared to fully substituted quinones; we chose the highly symmetric dimethoxy system 2,6-dimethoxy-1,4-benzoquinone (2,6-DBQ) as a model for naturally occurring quinone compounds [18]. In this study, we focus on spectroscopic properties as well as the electronic structure and hyperfine couplings of the primary radical which is formed in the initial phase of the hydroxylation reaction, and which plays a pivotal role in the transformation of 2,6-DBQ. Our goal is to fully describe the observed hyperfine interactions by applying density functional theory (DFT) methods and to derive by calculation of the isotropic coupling term, which is known as an extremely rigorous test of the quality of the wave function [19], a valid structural model of the prevailing radical in solution.

\section{Methods}

\subsection{EPR spectroscopy and sample preparation}

EPR is the method of choice to investigate radicals produced in chemical or biological processes. It allows obtaining a model of the radical structure and maps the wave function of the unpaired electron via the $g$-factor and the hyperfine couplings. X-band EPR spectra were measured at room temperature on a Bruker spectrometer E300 using a rectangular TMH cavity. The modulation amplitude was varied between 0.2 and $0.05 \mathrm{G}$ at $100 \mathrm{kHz}$ frequency, and the microwave power was set to 2 or $6.3 \mathrm{~mW}$. Simulation of the liquid phase spectra was performed using Simfonia or XSophe (Bruker).

A commercial 2,6-dimethoxy-1,4-benzoquinone (2,6DBQ) sample (Sigma) was dissolved in proper amounts of aqueous sodium hydroxide solution at $\mathrm{pH}$ of 12,13 and 14 to final concentrations of $20,10,5$ and $2.5 \mathrm{mM}$. This reaction mixture was usually prepared under aerobic conditions and filled into a $100 \mu \mathrm{L}$ quartz flat cell (Wilmad) for immediate measurement. To observe the influence of molecular oxygen on the reaction, the experiments were additionally carried out under anaerobic conditions in a glove box (McCoy) containing $5 \% \mathrm{H}_{2}$ gas and nitrogen. For degassing, the sodium hydroxide solution was shortly bubbled with Argon and remained in the reducing atmosphere for about $1 \mathrm{~h}$. Inside the glove box, the reaction solution was filled into the flat cell which was closed with gastight stoppers for the EPR experiment.

\subsection{Computational details}

All calculations, including geometry optimisations and EPR hyperfine couplings, were performed using DFT methods as implemented in the Gaussian 09 [20] software package. The structures were first fully optimised with $6-311 \mathrm{G}(\mathrm{d}, \mathrm{p})[21]$ basis set using the Becke's threeparametric hybrid exchange functional $[22,23]$ combined with the Lee-Yang-Parr correlation functional [24] at unrestricted level. The optimised structures were then checked for having imaginary frequencies indicating whether the structure is in a true minimum on the potential energy surface or whether it is a transition state structure.

Because the type of the basis set has a crucial effect on the net spin populations on a radical and, hence, on the isotropic hyperfine coupling values, the specially designed EPR-III basis set by Barone [25] and a Pople type triple zeta basis set with both polarisation and diffuse functions (on p and d orbitals), $(6-311++\mathrm{G}(\mathrm{d}, \mathrm{p})$ $[26,27]$ were applied to calculate the EPR parameters. The Pople basis set was used for calculating charge and spin distributions. This procedure was applied to the model molecules in the gas phase and in the presence of solvent. In the latter case, effects of bulk solvent and specifically placed water molecules were considered in implicit and explicit treatments, respectively.

The orientation of the methoxy groups of 2,6-DBQ was systematically altered by varying the dihedral angle of $-\mathrm{OCH}_{3}$ relative to the $\mathrm{C} 3=\mathrm{C} 6($ and $\mathrm{C} 4=\mathrm{C} 5)$ bond of the ring system (cf. Figure 2(a)). The rotation of the methyl protons of the methoxy group was also included to obtain the averaged isotropic values. For this kind of averaging, the procedures suggested by Mattar et al. [28] and Ban et al. [29] were used. First, the isotropic couplings $a_{\text {iso }}\left({ }^{1} \mathrm{H}\right)$ for each methyl proton at each of the five torsion angles between $0^{\circ}$ and $120^{\circ}$ (i.e. step width of $30^{\circ}$ ) were calculated. According to Equation (1), for each of the $n$ torsion angles, the averaged $\left\langle a_{\text {iso }}\left({ }^{1} \mathrm{H}, n\right)\right\rangle$ values were obtained. These were then rotationally averaged with Equation (2) over the entire range of the torsion angles to give the final isotropic hyperfine value of freely rotating methyl protons.

$$
\begin{aligned}
\left\langle a_{\text {iso }}\left({ }^{1} H, n\right)\right\rangle & =\frac{a_{\text {iso }}(H 14)+a_{\text {iso }}(H 15)+a_{\text {iso }}(\mathrm{H} 16)}{3} \\
\left\langle a_{\text {iso }}\left({ }^{1} \mathrm{H}\right)\right\rangle_{\text {rot }} & =\frac{\sum_{n=0}^{n=4}\left\langle a_{\text {iso }}\left({ }^{1} \mathrm{H}, n\right)\right\rangle}{5}
\end{aligned}
$$




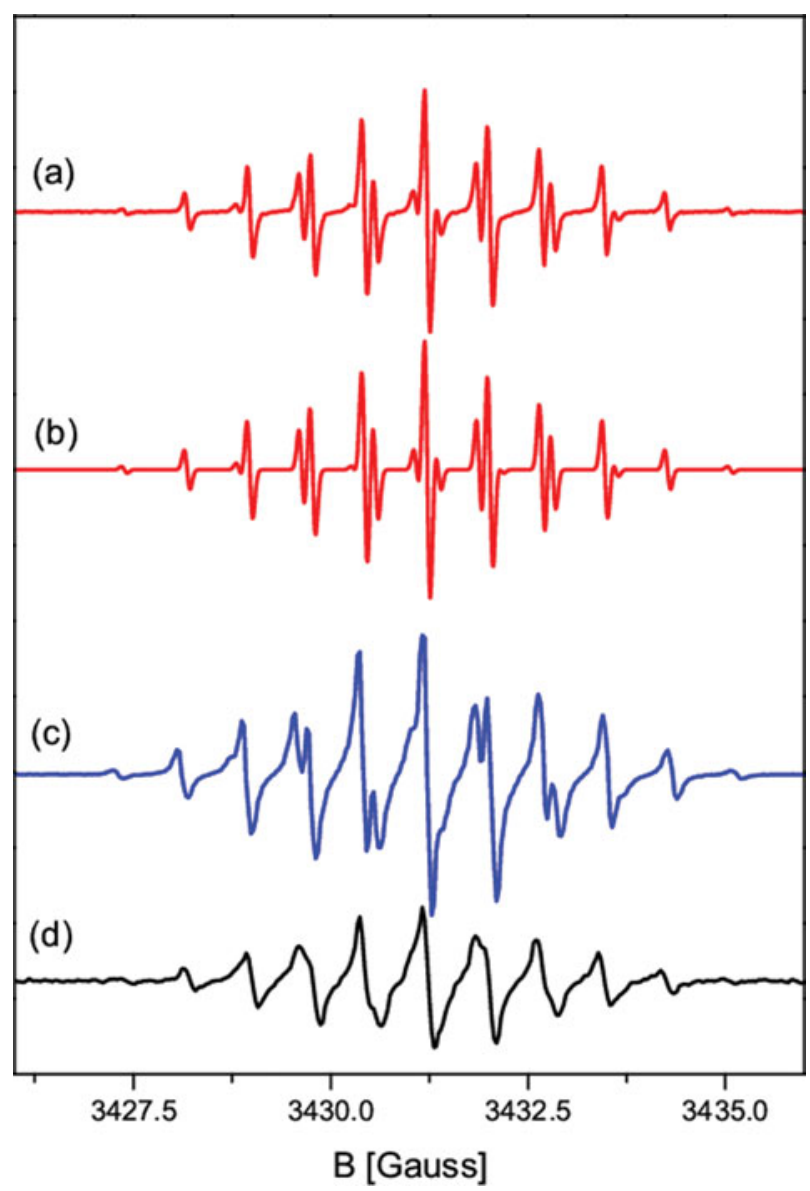

Figure 1. (a) The highly resolved spectrum of 2,6-DBQ recorded at $\mathrm{pH} 13$ with $2 \mathrm{~mW}$ microwave power and $0.05 \mathrm{G}$ modulation amplitude shows 11 major resonances. (b) The simulation corresponds to six equivalent methyl protons and two equivalent quinoid protons. (c) For higher concentration ( $5 \mathrm{mM}$ ) and/or larger modulation amplitude $0.1 \mathrm{G}$, the lines appear broadened. (d) At neutral pH in the presence of a strong reductant $\left(\mathrm{NaBH}_{4}\right)$, the same eleven line pattern is recorded.

Because the rotation of the methyl protons is expected to affect the coupling of the ring protons by altering the core polarisation, the averaging method has been applied to all structural models.

\section{Results and discussion}

\subsection{EPR spectra and simulations}

Exposure of 2,6-dimethoxy-1,4-benzoquinone (2,6$\mathrm{DBQ})$ to aqueous alkaline solution with $\mathrm{pH}$ of 12 or 13 leads to the formation of a primary radical showing an isotropic EPR spectrum with 11 major resonances (Figure 1(a)). For extended times ( $>1 \mathrm{~h}$ ), this radical loses intensity and is replaced by a secondary radical with a changed line pattern. Both radicals vanish when the solution is agitated or frozen, presumably because of recombination reactions and dimers formation. In this study, we focus on structural and electronic features of the primary radical observed in the alkaline environment. The resolution of its signals in Figure 1 is depending on the applied modulation amplitude and the initial concentration of 2,6-DBQ (Figure 1). For a modulation of $0.05 \mathrm{G}$ (and diluted sample), a highly resolved pattern is recorded, which can be simulated with isotropic hyperfine constants of six equivalent methyl protons $(\mathrm{A}(\mathrm{OCH} 3)=0.795 \mathrm{G})$ of both methoxy groups and of two equivalent quinoid protons with $\mathrm{A}(\mathrm{H})=1.453 \mathrm{G}$ (Figure 1(b) and Table 1). The less resolved spectrum in Figure $1(\mathrm{c})$ is simulated with nearly identical hyperfine parameters $(\mathrm{A}(\mathrm{H})=1.448 \mathrm{G}$, $\mathrm{A}(\mathrm{OCH} 3)=0.820 \mathrm{G})$ and slightly increased line width. Exclusion of oxygen from the reaction mixture at $\mathrm{pH}=$ 13 did not change the spectral evolution and patterns. Moreover, in fully deuterated alkaline environment $\left(\mathrm{D}_{2} \mathrm{O} / \mathrm{NaOD}\right)$, the identical pattern was recorded precluding the presence of exchangeable protons in the structure. The eleven line spectrum is also obtained for 2,6-DBQ, dissolved at neutral $\mathrm{pH}$ and reduced with the strong reductant $\mathrm{NaBH}_{4}$ (Figure 1(d)). These findings together with the spectra simulation, which reveal the presence of two methyl groups and two protons, clearly imply that the primary radical corresponds to the one electron reduced native form of 2,6-DBQ.

This result agrees well with the proposed reaction pathways of non-substituted or partially substituted benzoquinones in aqueous alkaline solutions $[16,17]$ postulating that the reaction starts with the addition of hydroxide to the native 2,6-DBQ (I) through a Michael addition (see Scheme 1) at an un-substituted ring position.

The mono-anion $\mathrm{II}^{-}$produced in this step and its dianion form $\mathrm{II}^{2-}$ are in equilibrium. The latter serves as a reductant and delivers an electron to compound I. As a result, the primary radical $\mathrm{I}^{{ }^{-}-}$is formed, which is associated with the eleven line EPR spectrum. The simultaneously generated mono-anion radical $\mathrm{II}^{--}$is unstable and, in addition, reduces the neutral form I to produce $\mathrm{I}^{{ }^{-}-}$ again. The resulting product, so far, is then the monohydroxylated 2,6-DBQ $\left(\mathrm{III}^{-}\right)$from which no indications as a radical are observed in the time evolution of the EPR spectra, and which is the starting point for generation of the secondary radical not considered here. It is noted that the primary radical is tightly linked to the formation of species III.

\subsection{Calculations of isotropic hyperfine couplings}

Having established the interactions of all protons of the 2,6-DBQ anion radical $\left(\mathrm{I}^{-}-\right)$, our goal then was to determine the radical structure by DFT for which the 
Table 1. Summary of calculated isotropic hyperfine couplings ${ }^{\mathrm{a}}$ for 2,6-dimethoxy-1,4-benzoquinone radical.

\begin{tabular}{|c|c|c|c|c|c|}
\hline No. & $\begin{array}{c}\text { Model } \\
\text { Experimental }\end{array}$ & $\begin{array}{c}a^{\text {iso }}\left({ }^{1} \mathrm{H} \alpha\right)^{b} \\
1.453\end{array}$ & $\begin{array}{c}a^{\text {iso }}\left({ }^{1} \mathrm{H} \gamma\right)^{b} \\
0.795\end{array}$ & $\Delta_{\text {tot }}{ }^{d}$ & Optimised structure \\
\hline $\begin{array}{l}1 \\
2\end{array}$ & $\begin{array}{l}\text { Gas phase } \\
\text { In PCM }\end{array}$ & $\begin{array}{l}-1.777(+0.324)^{c} \\
-1.668(+0.215)\end{array}$ & $\begin{array}{l}0.674(-0.121) \\
0.645(-0.150)\end{array}$ & $\begin{array}{l}0.445 \\
0.365\end{array}$ & \\
\hline $\begin{array}{l}3 \\
4\end{array}$ & $\begin{array}{c}\text { Gas phase }+ \text { random } \mathrm{H}_{2} \mathrm{O} \\
\text { In PCM }\end{array}$ & $\begin{array}{l}-0.757(-0.696) \\
-0.744(-0.709)\end{array}$ & $\begin{array}{l}0.816(+0.021) \\
0.775(-0.020)\end{array}$ & $\begin{array}{l}0.717 \\
0.729\end{array}$ & \\
\hline $\begin{array}{l}5 \\
6\end{array}$ & $\begin{array}{c}\text { Gas phase }+ \text { random } \mathrm{H}_{2} \mathrm{O} \\
\text { In PCM }\end{array}$ & $\begin{array}{l}-1.516(+0.063) \\
-1.417(-0.036)\end{array}$ & $\begin{array}{l}0.590(-0.205) \\
0.590(-0.205)\end{array}$ & $\begin{array}{l}0.269 \\
\mathbf{0 . 2 4 1}\end{array}$ & \\
\hline $\begin{array}{l}7 \\
8\end{array}$ & $\begin{array}{c}\text { Explicit water (@2.5 } \AA) \\
\text { Explicit water }(@ 2.5 \AA) \text { in PCM }\end{array}$ & $\begin{array}{l}-1.742(+0.289) \\
-1.358(-0.095)\end{array}$ & $\begin{array}{l}0.497(-0.298) \\
0.592(-\mathbf{0 . 2 0 3})\end{array}$ & $\begin{array}{l}0.587 \\
0.298\end{array}$ & \\
\hline $\begin{array}{l}9 \\
10\end{array}$ & $\begin{array}{c}\text { Explicit water (@4.0 } \AA) \\
\text { Explicit water (@4.0 } \AA \text { ) in PCM }\end{array}$ & $\begin{array}{c}-1.592(+0.139) \\
-1.486(+\mathbf{0 . 0 3 3})\end{array}$ & $\begin{array}{l}0.565(-0.230) \\
0.558(-0.237)\end{array}$ & $\begin{array}{l}0.369 \\
0.270\end{array}$ & \\
\hline
\end{tabular}

${ }^{a}$ Isotropic hyperfine couplings obtained at UB3LYP/6-311++G(d,p) // UB3LYP/6-311G(d,p) level (in Gauss).

${ }^{\mathrm{b}}$ Methyl protons are denoted by $\mathrm{H} \gamma$ and ring protons by $\mathrm{H} \alpha$.

'Numbers in parentheses give the differences of absolute calculated value to exp. value.

${ }^{\mathrm{d}}$ Total deviation as sum of absolute individual differences.

calculated hyperfine coupling constants (hfcs) optimally converge at the experimental values. For that purpose, the molecule was investigated in gas and aqueous phases including effects of $\mathrm{H}$-bonding on the hfc by considering explicit water molecules in its vicinity. In addition, the orientation of methoxy groups was taken into account, because these group(s) may affect the electronic properties [30] and, as a consequence, the redox potentials [31] as well as the vibrational frequencies of such quinone compounds $[32,33]$. In the case of 2,6-DBQ, it was found by Robinson and Kahn [30] that it is the interplay between three factors which affect the methoxy orientation toward the ring, the orbital delocalisation from methoxy oxygen to the quinone ring, the Coulombic repulsion between the lone pairs of methoxy and carbonyl oxygens and finally the steric interaction between methoxy methyl group and carbonyl group. In the ground state, it is mostly the delocalisation factor which governs the interactions, but for the semi-quinone form, delocalisation contributions are attenuated and outweighed by Coulombic interactions due to the increase of electron density around the carbonyl oxygen. 


<smiles>COC1=CC(=O)C(O)C(OC)=C1[O-]</smiles><smiles>COC1=C([O-])C(OC)=C([O-])C(=O)C1=O</smiles>

I

$\mathrm{II}^{-}$

$\mathrm{II}^{2-}$

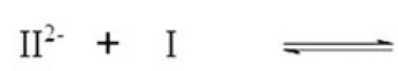<smiles>COc1ccc([O-])cc1[O-]</smiles>

$\mathrm{I}^{-}$<smiles>COC1=CC(=O)C([O])C(OC)=C1[O-]</smiles>

$\mathrm{II}^{-}$



III

Scheme 1. The proposed mechanism for the primary radical formation. Methoxy groups are represented by 'OMe.'

\subsubsection{Gas phase models}

In the first model, the orientations of the methoxy groups were varied between $0^{\circ}$ and $180^{\circ}$ in $10^{\circ}$ steps for the dihedrals $\Theta 1(\mathrm{C} 4, \mathrm{C} 5, \mathrm{O} 11, \mathrm{C} 13)$ and $\Theta 2(\mathrm{C} 3, \mathrm{C} 6, \mathrm{O} 12, \mathrm{C} 17)$ (Figure 2(a)). The resulting hfc values for this variation of the methoxy groups in model 1 are presented in Figure 2 (black curves, and supplementary material Table $\mathrm{S} 1)$. The hfc of the ring protons (H9, H10) shows a sinusoidal variation with a minimum at around $130^{\circ}$ (Figure 2(b)), whereas, the simple averaged methyl proton coupling is more distorted and reaches a minimum at about $70^{\circ}$ (Figure 2(c)). Performing an averaging of the hfcs for the methoxy dihedral angles, i.e. assuming rotating methoxy groups, produces hfc values of $-2.2 \mathrm{G}$ for H9, 10 , but only about $0.2 \mathrm{G}$ for the methyl protons. These values are far off the experimental ones so that a rotating methoxy group can be safely excluded. For both proton groups in model 1, the hfc values closest to experiment were obtained when both methoxy groups were located in or close to the ring plane $\left(\Theta 1,2=0^{\circ} \pm 20^{\circ}\right)$. This $0^{\circ}$ in-plane configuration (or $0^{\circ}$-conformer) was then used to estimate the isotropic hfc of freely rotating methyl groups. Figure 2(d) presents the variation of methyl protons (at $\mathrm{C} 13$ ) as a function of the dihedral angle $\Theta 3(\mathrm{C} 5, \mathrm{O} 11, \mathrm{C} 13, \mathrm{H} 15)$. Due to the intrinsic symmetry, the hfc of the three methyl protons shows a sinusoidal variation, and the averaged values for $\Theta 3$ angles are nearly constant. The same trend was found for variation of the dihedral angle $\Theta 4(\mathrm{C} 6, \mathrm{O} 12, \mathrm{C} 17, \mathrm{H} 19)$. The rotational average $(0.674 \mathrm{G}$, see Figure $2(\mathrm{~d}))$ over the whole range is in reasonable agreement with the measured value of $0.795 \mathrm{G}$ (Table 1 , model 1 , in the table the differences to the experimental values are additionally given in parentheses). By averaging the values for $\mathrm{H} 9$ and $\mathrm{H} 10$ for each methyl rotation step of this configuration, one obtains the ring proton coupling value of $-1.777 \mathrm{G}$ which is consistent with but still larger than the experimental value, $1.453 \mathrm{G}$. As expected for an $\alpha$-proton of a ring structure, the calculated hfc adopts a negative value (Table 1 , model 1).

In the next step, the polarised continuum model (PCM) by Tomasi and co-workers [34], as it is implemented in G09, was applied to model the dielectric effects of water as a solvent. The resulting hfcs show only a slight modification for the ring and methyl protons towards lower values (Table 1, model 2). It is noted here that hyperfine couplings were calculated with both the 6-311++G(d,p) and the specially designed EPR-III basis sets which did not show significant differences. The Pople basis set is further discussed here. The EPRIII results for gas phase calculations can be found in Table S1. 

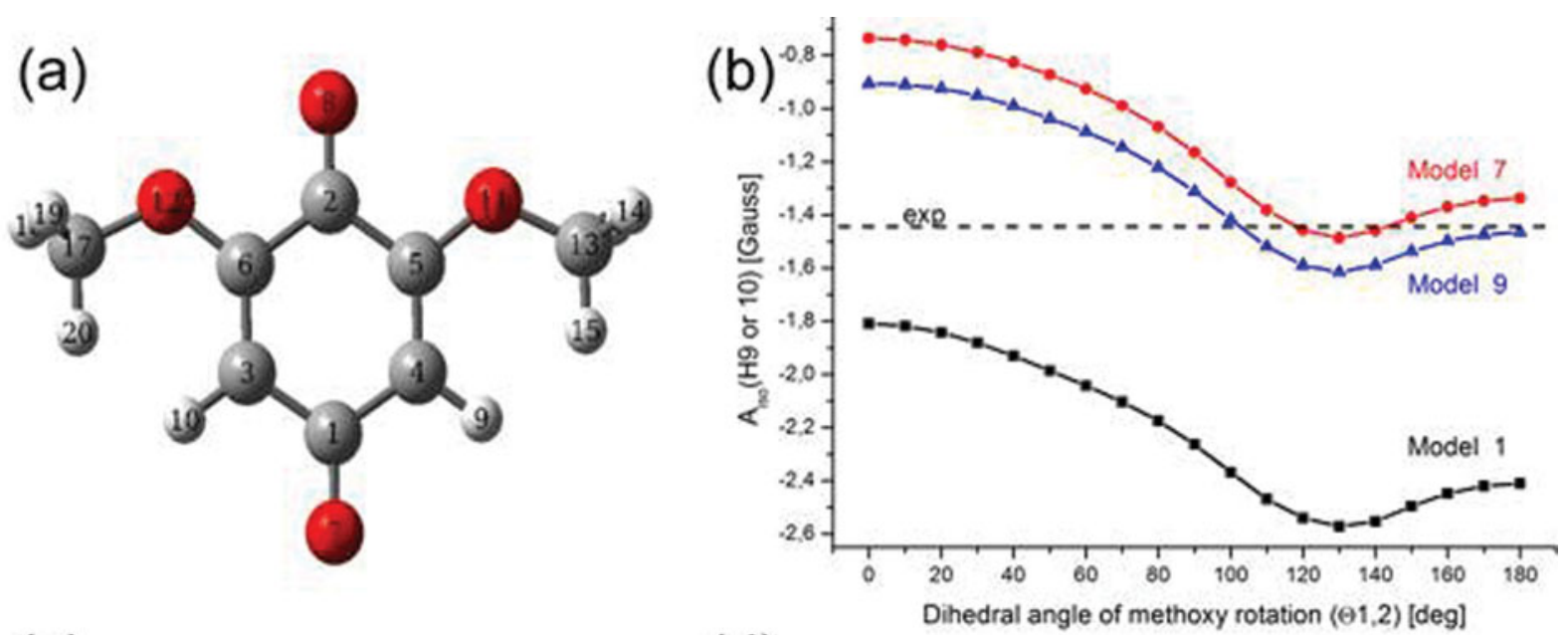

(c)

(d)
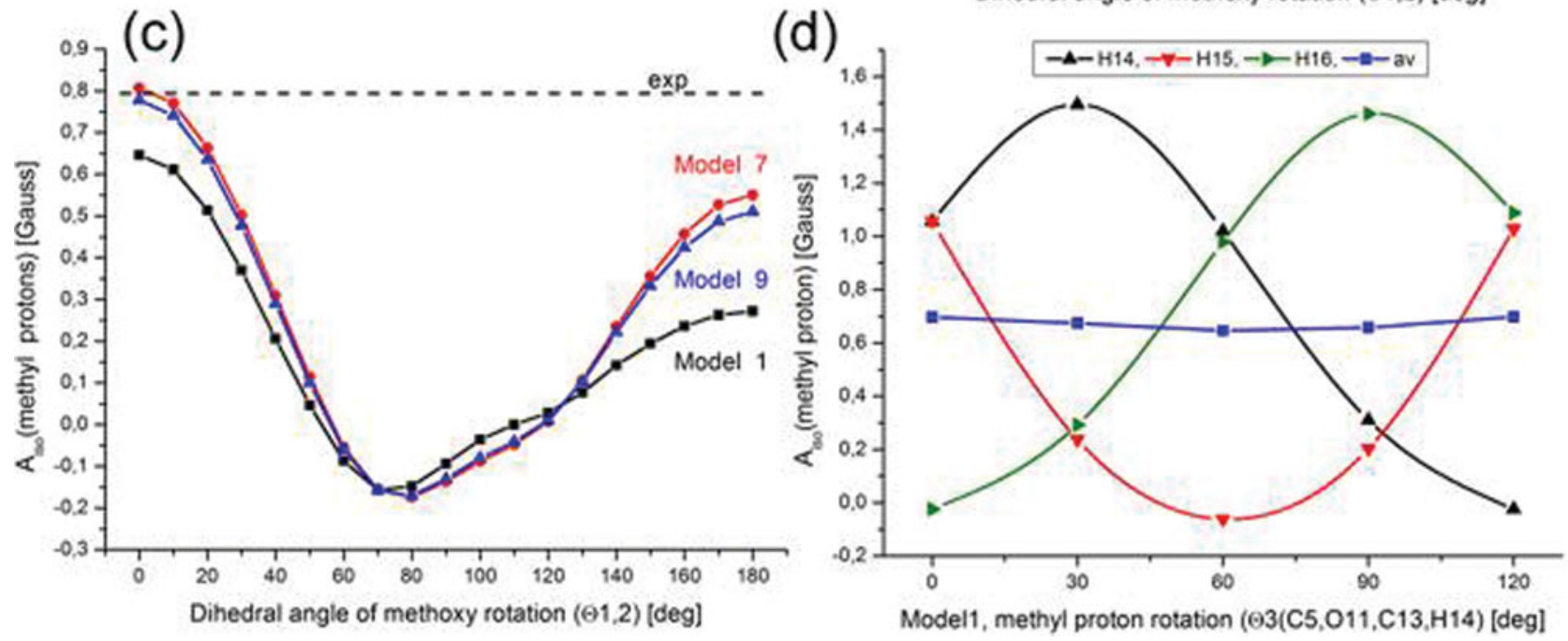

Figure 2. (a) The optimised gas phase structure of model 1. The atomic numbering for model 1 is also used for the other models. Variation of the quinoid proton hfc (b) and the methyl proton hfc (c) as a function of the methoxy dihedral angles $\theta 1(\mathrm{C} 4, \mathrm{C} 5,011, \mathrm{C} 13)$ and $\theta 2(\mathrm{C} 3, \mathrm{C} 6,012, \mathrm{C} 17)$ for model 1 (black curves). The experimental couplings are indicated by the dashed lines for each group of protons. The curves for models 7 and 9 are discussed in the text. (d) Isotropic hyperfine coupling constants of the methyl protons were calculated for model 1 as a function of dihedral angle $\theta 3(\mathrm{C} 5,011, \mathrm{C} 13, \mathrm{H} 15)$ with the methoxy groups fixed in the in-plane configuration $(\theta 1,2=0)$. Because C2 symmetry was preserved during the calculations, methyl protons of both methoxy groups show the same trend.

\subsubsection{Addition of explicit water molecules to the gas phase model}

In a further step, the gas phase models 1 and 2 were extended by arbitrarily placing water molecules near the structure at three possible locations: close to (1) carbonyl C2O8 (cf. Figure 2(a)), (2) both methoxy groups and (3) in the vicinity of carbonyl $\mathrm{C} 1 \mathrm{O} 7$ near the ring protons. Test calculations produced hfc values rather divergent from the experimental data for the first two locations. Therefore, we focused on the model with water molecules close to C1O7. For this location, the methoxy dihedrals were kept fixed, however, the water molecules were free to move. After a full optimisation and hfc calculations, structures were again optimised using the PCM model and hfcs were calculated. This procedure was applied to the structures, in which the methoxy groups are in-plane (i.e. methoxy dihedrals are either $0^{\circ}$ or $180^{\circ}$ ). The conformer with $\Theta 1,2=0^{\circ}$ (Table 1, model 4) reproduces well the methyl proton couplings $(0.775 \mathrm{G})$, but the ring protons are only half the experimental value $(-0.744 \mathrm{G})$. The second conformer $\left(\Theta 1,2=180^{\circ}\right.$, Table 1, model 6) with randomly placed water molecules yields a value for ring proton couplings $(-1.417 \mathrm{G})$ close to the experiment, but the methyl proton coupling is a bit away from the experimental one $(0.590 \mathrm{G})$.

The deviations of calculated values for models 3-6 led us to check the relative energies depending on the distances between ring protons and the water oxygens which were scanned in $0.5 \AA$ steps between 1.5 and $5.0 \AA$. No restrictions were applied on the methoxy dihedrals. Figure 3(a) reveals two minima in energy when the water oxygens are located at 2.5 and $4.0 \AA$ from the ring protons 


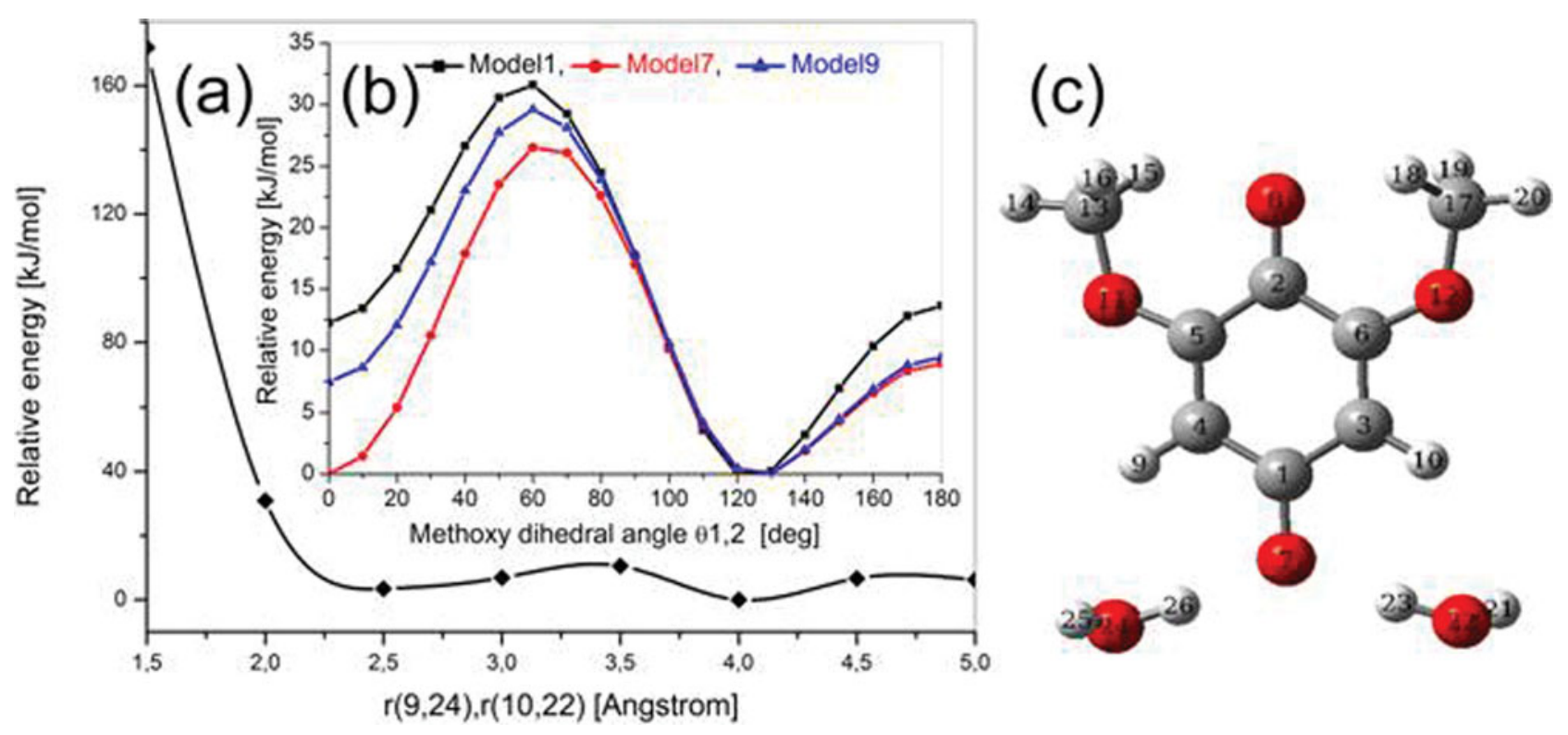

Figure 3. (a) Energy profile as a function of the distance between oxygen atom of water molecules and ring proton sites $r_{1}(9,24)$ and $r_{2}$ $(10,22)$. (b, inset) Rotational profiles of energy in terms of methoxy dihedrals for models 1 (gas phase), 7 (distance $2.5 \AA$ ) and 9 (distance $4 \AA$ Å). (c) Shows the fully optimised model 7 at UB3LYP/6-311G(d,p) level.

being different by $3.49 \mathrm{~kJ} / \mathrm{mol}$. The following calculations for the methoxy dihedral variation $\left(0^{\circ}-180^{\circ}\right)$ were performed with the water molecules fixed in their optimum positions ( 2.5 or $4.0 \AA$ ) producing the energy profiles in Figure 3(b), which correspond to models 1,7 and 9 in Table 1 . As expected, the gas phase curve shows more positive energy values than the curves for the explicit water models. For the latter two, H-bonding interactions possibly increase the stability of these structures. All curves have a maximum at $60^{\circ}$ while the gas phase model reaches a minimum at $120^{\circ}$ which broadens towards $130^{\circ}$ for the other two curves. The maximum energy state can be related to the deficient overlap between the methoxy oxygen lone pair and the $\pi$-system. The decrease in the Coulombic repulsion is reflected in the downward trend of energy curve which gradually falls off from $60^{\circ}$ to the minimum at $120^{\circ}$ (or $130^{\circ}$ in the other two cases). Eventually, the steric interactions between methyl from methoxy and carbonyl groups cause the higher energy of the structure with $\Theta 1,2=180^{\circ}$ [30]. The heights of the rotational barriers between the maximum and minimum states are $31.600,26.484$ and $29.594 \mathrm{~kJ} / \mathrm{mol}$ for the gas phase and the explicit water models 7 and 9, respectively. The gas phase value is close to the one previously reported by Robinson and Kahn [30] (37 kJ/mol, using Hartree-Fock method) and is in excellent agreement with values obtained by configuration interaction methods used by Burie et al. (32 kJ/mol) [32].

As can be inferred from Figure 3(b), another minimum is observable at $0^{\circ}$ of the $-\mathrm{OCH} 3$ orientation for model 7. These two minima (at $0^{\circ}$ and $130.0^{\circ}$ ) are very similar in terms of energy, the $0^{\circ}$-conformer being slightly higher by about $0.004 \mathrm{~kJ} / \mathrm{mol}$ compared to the $130^{\circ}$-conformer. It is interesting to note that the $0^{\circ}$-conformer reproduces the hfcs for methyl protons $(0.775 \mathrm{G}$, obtained by methyl rotational averaging) and that the $130^{\circ}$-conformer agrees well with experimental values of ring protons $(-1.487 \mathrm{G})$, but none of them alone give the values for ring protons and methyl protons simultaneously. This behaviour is visualised for both quinoid and methyl protons in Figure 2(b) and 2(c) showing their mutual deviations from the experimental values (see also Table S1). For model 7, the influence of water molecules shifts the curve of quinoid protons $\mathrm{H} 9$, H10 much closer to the experimental values as compared to model 1 (Figure 2(b)). In analogy to this model, a rotating methoxy group is excluded. Considering the closeness in energy for the two conformers $\left(0^{\circ}\right.$ and $\left.130.0^{\circ}\right)$ and the small magnitude compared to thermal energy $K_{\mathrm{B}} T$ value at $298 \mathrm{~K}(\approx 2.5 \mathrm{~kJ} / \mathrm{mol})$, one may think of an interconversion between the conformers. Regarding the rotational barrier between the energetically equivalent states of model 7, the inter-conversion is supposed to be rather slow on the timescale of EPR. In that case, one should observe superimposed spectra (or distorted or broadened spectral lines) resulting from the presence of both conformers, which, however, were not found in our experiments.

Consequently, the compromise candidate is the $180^{\circ}$ conformer for which the calculated couplings are in 
reasonable agreement with experiment. Performing the methyl rotational averaging yields a value of $-1.742 \mathrm{G}$ for ring protons and $0.497 \mathrm{G}$ for methyl protons. In Table 1, models 7 and 8 , the averaged values and their deviations are listed. However, from an energetic point of view, this conformer is not a minimum energy state, and one might, therefore, consider fluctuations of the methoxy group around the $180^{\circ}$ configuration. The effect of a bulk dielectric medium on model 7 was again simulated using the PCM approach. In that case, the ring proton couplings shift to a lower value $(-1.358 \mathrm{G})$ (see Table 1 , model 8 ). The variation of methyl proton couplings in model 8 as a function of dihedral angle $\Theta 4(\mathrm{C} 6, \mathrm{O} 12, \mathrm{C} 17, \mathrm{H} 19)$ in PCM environment is showing a slightly curved averaged coupling as in Figure 2(b) yielding the total averaged value listed in Table 1.

The same process was performed for water localised at a distance of $4.0 \AA$ and the hfcs were calculated for this model 9, for which the $\mathrm{H} 9$ (H10) proton coupling is quite well reproduced by the $180^{\circ}$-conformer but shows about the same deviation for the methyl hfc as model 7 (Figure 2(c) and 2(d)). In analogy, the $180^{\circ}$-conformer was simulated in the dielectric medium (model 10). Applying again methyl proton averaging yields the values listed in Table 1 for models 9 and 10. The compiled data of Table 1 clearly show that the $0^{\circ}$-conformer of the methoxy orientation (models 1-4) produce the largest total deviations $\Delta_{\text {tot }}$ from the experimental values. The deviations significantly drop for the PCM models 6,8 and 10 for which the methoxy groups are placed within the ring plane in the $180^{\circ}$ position. The dielectric medium (PCM) predominantly affects the $\mathrm{H} \alpha$-contributions while the methyl proton interactions are changing minimally. To further reduce their deviations, additional water molecules were placed above and below the ring plane of model 6, letting them move freely during optimisation. For such configurations, the ring proton couplings shift to a lower hfc $(-1.272 \mathrm{G})$ while methyl protons are somewhat increasing to $0.603 \mathrm{G}$ so that the resulting deviations are not really improved (this model is not listed in Table 1). The minimal individual deviations are found for models 8 and 10 , and model 6 shows the smallest total deviation (bold numbers in Table 1). Because the $\Delta_{\text {tot }}$ values are differing only by $0.06 \mathrm{G}$, the three models may be considered equivalent.

Usually, at the end of each successful geometry optimisation, frequency calculations are performed to infer if the structure is a real minimum on the potential energy surface or not. From such calculations, for each of the models 6,8 and 10, two relatively small imaginary frequencies $\left(-58.751\right.$ and $-57.396 \mathrm{~cm}^{-1} ;-54.22$ and $-52.89 \mathrm{~cm}^{-1} ;-57.10$ and $-53.93 \mathrm{~cm}^{-1}$, respectively) are obtained, indicating only minor geometric distortions of the molecules. Examining the corresponding normal modes showed that these frequencies are mainly related to the methyl proton movements.

\subsubsection{H-bonding geometries}

The necessity to introduce explicit water molecules for optimising the hfcs implies to analyse the $\mathrm{H}$-bonding of the three models $(6,8$ and 10$)$, for which all details together with the definition of parameters are compiled in Table 2. The calculated $\mathrm{H}$-bond length $R_{\mathrm{O}} \ldots \mathrm{H}$ in PCM solvent for models 8 and 10 are 1.74 and $1.85 \AA$, respectively, and agree well with results reported for similar systems by O'Malley [35] (1.79 ̊ for a p-benzoquinone system with four water molecules) and by Sinnecker et al. [36] (1.74 $\AA$ for the case of a p-benzoquinone system with up to 20 water molecules) (see Table 2). For model 8, almost linear $\mathrm{H}$-bonds are found because the calculated angle $\Theta_{\mathrm{OHO}}$ value is close to $180.0^{\circ}$, whereas, model 10 deviates by about $20^{\circ}$ from a linear arrangement. The $\mathrm{H}$-bonds of model 8 are lying within the ring plane as indicated by the dihedral angle $\Theta_{\mathrm{HOCC}}$ of $-1.79^{\circ}$, while the second conformer (model 10) shows a tendency of tilted $\mathrm{H}$-bonds $\left(-14.48^{\circ}\right)$. For both models, the rather symmetric arrangement of the water molecules yields very similar geometric parameters of their hydrogen bonding. This is not the case for model 6 with randomly placed water molecules, the closer one $(3.7 \AA)$ showing a more tilted configuration and less linear $\mathrm{H}$ bond orientation than the more remote water $(4.3 \AA)$. However, the H-bonding lengths of 1.7 and $1.9 \AA$ are definitely within allowed distances (Table 2).

\subsubsection{Electronic structure}

According to Tables 1 and 2, the calculated hfcs of the quinoid protons $(\mathrm{H} \alpha)$ and the methyl protons of the methoxy groups $(\mathrm{H} \gamma)$ differ significantly depending on the orientation of the methoxy group and, in addition, on the presence of additional water molecules. For example, the formation of hydrogen bonds in model 3 or 4 vs. model 1 or 2 drastically changes the hfcs. Generally, the proton hfc depends on the electronic structure of the molecule, which is reflected by the single occupied molecular orbital (MO), the distribution of spin and of charge within the structure. For the latter, several studies $[37,38]$ have shown a pronounced effect of hydrogen bonding on the hfc. Therefore, the relevant factors will be discussed in more detail for some selected models.

Qualitative pictures of the single occupied $\alpha$ molecular orbital (SOMO) for the models $6,8,10$ and the gas phase structure (model 1) are shown in Figure 4. The unpaired electron resides in a $\pi$-type MO mainly localised on the ring system. It is bonded between carbon 
Table 2. Hydrogen bonding and structural geometries for 2,6-dimethoxy-1,4-benzoquinone radical anion obtained at UB3LYP/6$311 G(d, p)$ level. ${ }^{a}$

\begin{tabular}{|c|c|c|c|c|c|c|c|c|}
\hline$\Theta_{\mathrm{HOCC}}$ & $\varphi_{\mathrm{OHO}}$ & $\varphi_{\mathrm{COH}}$ & $R_{\mathrm{CO}}$ & $R_{0 \ldots \mathrm{H}}$ & $R_{0} \ldots 0$ & $R_{\mathrm{C}-\mathrm{C}}$ & $R_{\mathrm{C}=\mathrm{C}}$ & Comments \\
\hline & & eometric & itions & & & & & \\
\hline \multicolumn{9}{|c|}{ Model 6} \\
\hline-17.71 & 166.77 & 120.25 & 1.28 & 1.90 & 2.79 & 1.46 & 1.38 & PCM,-right side $\mathrm{H}$-bond $\mathrm{H}_{\text {ring }}-\mathrm{O}_{\mathrm{w}}=4.3 \AA$ \\
\hline 59.04 & 150.76 & 133.05 & 1.28 & 1.72 & 2.70 & 1.46 & 1.38 & PCM,-left side $\mathrm{H}$-bond $\mathrm{H}_{\text {ring }}-\mathrm{O}_{\mathrm{W}}=3.7 \AA$ \\
\hline \multicolumn{9}{|c|}{ Model 8} \\
\hline-1.79 & 173.80 & 113.07 & 1.29 & 1.74 & 2.73 & 1.46 & 1.37 & $\mathrm{PCM} \mathrm{H}_{\text {ring }}-\mathrm{O}_{\mathrm{W}}=2.5 \AA$ \\
\hline \multicolumn{9}{|c|}{ Model 10} \\
\hline-14.48 & 158.32 & 141.41 & 1.28 & 1.85 & 2.78 & 1.46 & 1.37 & $\mathrm{PCM} \mathrm{H}_{\text {ring }}-\mathrm{O}_{\mathrm{W}}=4.0 \AA$ \\
\hline 2.50 & 171.00 & 127.00 & & 1.72 & & & & $\mathrm{BQ}^{\cdot-}-/ 2 \mathrm{~W}(\mathrm{EPR}-\mathrm{II})^{\mathrm{c}}$ \\
\hline \multirow[t]{3}{*}{7.20} & 165.00 & 112.00 & & 1.74 & & & & $\mathrm{BQ}^{\bullet}-/ 20 \mathrm{~W}(\mathrm{EPR}-\mathrm{II})^{\mathrm{c}}$ \\
\hline & & $121-124$ & 1.28 & 1.79 & & 1.44 & 1.37 & $\mathrm{BQ}^{\bullet}-/ 4 \mathrm{~W}\left(6-31+\mathrm{G}(\mathrm{d})^{\mathrm{d}}\right.$ \\
\hline & & & 1.29 & 1.78 & & 1.45 & 1.38 & $\mathrm{BQ}^{\bullet}-/ 4 \mathrm{~W}(\mathrm{EPR}-\mathrm{III})^{\mathrm{d}}$ \\
\hline
\end{tabular}

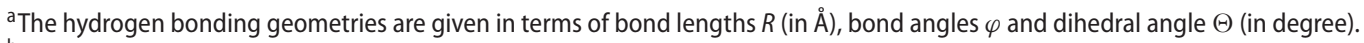

${ }^{\mathrm{b}}$ Adapted from ref. [36].

'From ref. [36].

${ }^{d}$ From ref. [35].

atoms attached to the methoxy groups and the carbonyl carbon atom (upper half of the structure). However, the SOMO of the carbonyl group is non-bonded between C2, O8. The same features are found for their counterpart atoms in the lower half of the structure $(\mathrm{C} 1, \mathrm{O} 7)$. It also can be seen in Figure 4 that the SOMO is non-bonded on the methoxy oxygen atoms. Comparing the SOMO of the four models, it is apparent that the $\mathrm{H}$-bonds introduced by the water molecules do not significantly alter the orbital shape.
Mulliken population analysis was used to provide a qualitative picture of charge and spin distributions within the molecular systems of the various models. The spin populations were calculated with the $6-311++G(d, p)$ basis set at the unrestricted B3LYP level (UB3LYP). It is noted here that for the reported values compiled in Table S2, rotational averaging of methyl protons was not considered (i.e. the values of the protons are for a single, but representative orientation). The most prominent feature is that the upper half of the molecule (with carbonyl (a)

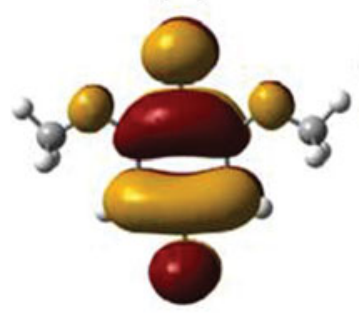

(b)

(c)



Figure 4. Single occupied molecular orbital for gas phase model 1 (a), for model 6 (b), model 8 (c) and model 10 (d) with explicit water calculated at UB3LYP/6-311++G(d,p) level, contoured at $0.002 \mathrm{e} / \mathrm{au}^{3}$. 
C2O8 and methoxy groups, cf. Figure 2(a)) holds about two-thirds of the spin population for all models reflecting the molecular asymmetry. In both parts, the majority of spin population is located on the carbonyl groups with more than 0.3 for $\mathrm{C} 2 \mathrm{O} 8$ and around 0.3 for $\mathrm{C} 1 \mathrm{O} 7$ which matches the finding that in ortho- and para-semiquinone anions, over $60 \%$ of the spin population are concentrated on these groups [39,40]. Addition of two water molecules to model 1 (or 2) induces a slight increase of spin population in the upper half and a minor rearrangement within the methoxy groups but a more pronounced change for the quinoid protons ( $\mathrm{H} 9, \mathrm{H} 10)$, which seems to correlate to the drastic decrease of the $\mathrm{H}-\alpha$ coupling off from the experimental values (Table 1 , model 4 ). These couplings are restored on going to the $180^{\circ}$-conformer, obviously associated with an increase of the quinoid carbon and proton spin densities in models 6,8 and 10. On the other hand, for these models, the spin population on the methoxy group atoms is clearly reduced which correlates with the decrease in hfc of the methyl protons. In this context, it is noteworthy that the carbonyl spin population (at C2O8) significantly rises to about 0.45 for models 6-10 compared to model 4 with about 0.34 and, thus, may partly compensate for the reduction of the methyl proton hfc.

Natural population analysis (NPA) as implemented in G09 software package was applied to study the charge distribution over the molecule divided into different fragments, i.e. two methoxy groups, two carbonyl groups and two $\mathrm{CH}$ bonds, in addition to the two water molecules. The charge of carbon atoms bound to the methoxy groups is included within the methoxy fragment charges. For model 8 , going from gas phase to the $\mathrm{H}$-bonded complex, the carbonyl groups gain some negative charge, while the other groups (the two $\mathrm{CH}$ and methoxy groups) become more positive. On average, 0.045 electrons are transferred from these donating groups to each $\mathrm{H}$-bonded water molecule. This is a reasonable value for such a radical system $\left(\mathrm{C} 8 \mathrm{H} 2 \mathrm{O}^{-}{ }^{-} .2 \mathrm{w}\right)$ and similar to the value of 0.06 electron transferred to water molecules reported by Chipman for the related system $\mathrm{C} 6 \mathrm{H} 4 \mathrm{O}_{2}{ }^{-} .4 \mathrm{w}$ (p-benzoquinone anion radical) [37]. The same procedure was applied to models 6 and 10. In these cases, the amount of charge transfer per $\mathrm{H}$-bonded water molecule was calculated as 0.036 and 0.030 , respectively.

\section{Conclusions}

In this report, the primary radical of 2,6-dimethoxy-1,4benzoquinone generated by a single electron transfer in alkaline medium was analysed in detail by DFT methods to obtain insights into the structure of this transient species. The isotropic hfc of the six methyl protons and both quinoid ring protons of the primary 2,6-DBQ radical provides the reference point to scan, at least in parts, the configuration space of the molecule for an optimal congruence of the calculated couplings. It was found that the rotation of the methoxy and methyl protons together with the presence of water molecules close to one carbonyl group cause a significant improvement of calculated couplings with respect to the simple gas phase model. The best models are defined by the $180^{\circ}$ position of the methoxy groups which possibly can fluctuate around this position. The water molecules are best located close to the opposite carbonyl group adopting defined positions according to the energy calculations. Their polarity and hydrogen bonding strongly affect the ring proton couplings, and, to a lesser extent, also the methyl protons shifting both closer to the experimental values. Because the radical plays a pivotal role in the transformation reaction but cannot be sufficiently stabilised to apply additional structure resolving techniques such as electron-nuclear double resonance or electron spin echo spectroscopies, the theoretical approach allows gaining information on the otherwise inaccessible structural features. It also will be applied to the secondary radicals observed in hydroxylation reactions of 2,6-DBQ. Our theoretical approach is relevant to better understand the physico-chemical properties and the reactivity of the biologically important, partially substituted quinoid compounds and fully substituted coenzymes such as $\mathrm{Q}_{1}$ and $\mathrm{Q}_{10}[15,17]$.

\section{Disclosure statement}

No potential conflict of interest was reported by the authors.

\section{Funding}

DFG [GRK 845 to H. Haeri], [SFB 894 to M. Hoth], [SFB1027 C4 to I. Bogeski], [Ka 1242/1-1 to R. Kappl]; Saarland University [HOMFOR to I. Bogeski]; AvH foundation via the joint German-Macedonian project [3.4-Fokoop-DEU/1128670 to V. Mirceski, R. Gulaboski, I. Bogeski and M. Hoth].

\section{References}

[1] D.I. Davies and M.J. Parott, Reactivity and Structure Concepts in Organic Chemistry (Springer, Berlin, 1978).

[2] J. Fossey, D. Lefort, and J. Sorba, Free Radicals in Organic Chemistry (Wiley, Chichester, 1995).

[3] H.S. Bisht and A.K. Chatterjee, J. Macromol. Sci.: Polym. Rev. C41(3), 139-173 (2001).

[4] M. Buback and A.L. German, Macromol. Symp. 182, 103 (2002). 
[5] R. Improta and V. Barone, Chem. Rev. 104 (3), 1231-1254 (2004).

[6] O. Ito, in General Aspects of the Chemistry of Radicals, edited by Z.B. Alfassi (Wiley, New York, 1999).

[7] R.G. Efremov, R. Baradaran, and L.A. Sazanov, Nature 465 (7297), 441-445 (2010).

[8] R. Fato, C. Bergamini, M. Bortolus, A.L. Maniero, S. Leoni, T. Ohnishi, and G. Lenaz, Biochim. Biophys. Acta 1787 (5), 384-392 (2009).

[9] R. Horsefield, V. Yankovskaya, G. Sexton, W. Whittingham, K. Shiomi, S. Omura, B. Byrne, G. Cecchini, and S. Iwata, J. Biol. Chem. 281 (11), 7309-7316 (2006).

[10] G. Lenaz and M.L. Genova, Biochim. Biophys. Acta 1787 (6), 563-573 (2009).

[11] K. Hensley and R.A. Floyd, Arch. Biochem. Biophys. 397 (2), 377-383 (2002).

[12] J. Stubbe and W.A. van der Donk, Chem. Rev. 98 (2), 705762 (1998).

[13] I.M. Bennett, H.M.V. Farfano, F. Bogani, A. Primak, P.A. Liddell, L. Otero, L. Sereno, J.J. Silber, A.L. Moore, T.A. Moore, and D. Gust, Nature 420 (6914), 398-401 (2002).

[14] V. Mirceski, R. Gulaboski, I. Bogeski, and M. Hoth, J. Phys. Chem. C 111 (16), 6068-6076 (2007).

[15] I. Bogeski, R. Guaboski, R. Kappl, V. Mirceski, M. Stefova, J. Petreska, and M. Hoth, J. Am. Chem. Soc. 133 (24), 9293-9303 (2011).

[16] J.A. Pedersen, J. Chem. Soc. Perkin Trans. 2 (4), 424-431 (1973).

[17] J.A. Pedersen, Spectrochim. Acta Part A: Mol. Biomol. Spectrosc. 58 (6), 1257-1270 (2002).

[18] H. Nohl, W. Jordan, and R.J. Youngman, Adv. Free Rad. Biol. Med. 2 (1), 211-279 (1986).

[19] S.M. Mattar, Chem. Phys. Lett. 300 (5-6), 545-552 (1999).

[20] M.J. Frisch, G.W. Trucks, H.B. Schlegel, G.E. Scuseria, M.A. Robb, J.R. Cheeseman, G. Scalmani, V. Barone, B. Mennucci, G.A. Petersson, H. Nakatsuji, M. Caricato, X. Li, H.P. Hratchian, A.F. Izmaylov, J. Bloino, G. Zheng, J.L. Sonnenberg, M. Hada, M. Ehara, K. Toyota, R. Fukuda, J. Hasegawa, M. Ishida, T. Nakajima, Y. Honda, O. Kitao, H. Nakai, T. Vreven, J.A.J. Montgomery, J.E. Peralta, F. Ogliaro, M. Bearpark, J.J. Heyd, E. Brothers, K.N. Kudin, V.N. Staroverov, R. Kobayashi, J. Normand, K. Raghavachari, A. Rendell, J.C. Burant, S.S. Iyengar, J. Tomasi, M. Cossi, N. Rega, J.M. Millam, M. Klene, J.E. Knox, J.B. Cross, V. Bakken, C. Adamo, J. Jaramillo, R. Gomperts, R.E. Stratmann, O. Yazyev, A.J. Austin, R. Cammi, C. Pomelli,
J.W. Ochterski, R.L. Martin, K. Morokuma, V.G. Zakrzewski, G.A. Voth, P. Salvador, J.J. Dannenberg, S. Dapprich, A.D. Daniels, Ö. Farkas, J.B. Foresman, J.V. Ortiz, J. Cioslowski, and D.J. Fox, Gaussian 09, Revision A.1 (Gaussian, Inc., Wallingford, CT, 2009).

[21] R. Krishnan, J.S. Binkley, R. Seeger, and J.A. Pople, J. Chem. Phys. 72 (1), 650-654 (1980).

[22] A.D. Becke, Phys. Rev. A 38 (6), 3098-3100 (1988).

[23] W. Koch and M.C. Holthausen, A Chemist's Guide to Density Functional Theory, 2nd ed. (Wiley-VCH, Weinheim, Germany, 2001).

[24] C.T. Lee, W.T. Yang, and R.G. Parr, Phys. Rev. B 37 (2), 785-789 (1988).

[25] V. Barone, in Recent Advances in Density Functional Methods, Part I, edited by D.P. Chong (World Scientific Publ. Co. Singapore, 1996).

[26] T. Clark, J. Chandrasekhar, G.W. Spitznagel, and P.V. Schleyer, J. Comput. Chem. 4 (3), 294-301 (1983).

[27] W.J. Hehre, R. Ditchfie, and J.A. Pople, J. Chem. Phys. 56 (5), 2257-2261 (1972).

[28] S.M. Mattar, A.H. Emwas, and A.D. Stephens, Chem. Phys. Lett. 363 (1-2), 152-160 (2002).

[29] F.Q. Ban, J.W. Gauld, and R.J. Boyd, J. Phys. Chem. A 104 (21), 5080-5086 (2000).

[30] H.H. Robinson and S.D. Kahn, J. Am. Chem. Soc. 112 (12), 4728-4731 (1990).

[31] R.C. Prince, P.L. Dutton, and J.M. Bruce, FEBS Lett. 160 (1-2), 273-276 (1983).

[32] J.R. Burie, C. Boullais, M. Nonella, C. Mioskowski, E. Nabedryk, and J. Breton, J. Phys. Chem. B 101 (33), 66076617 (1997).

[33] M. Nonella, J. Phys. Chem. B 102 (21), 4217-4225 (1998).

[34] S. Miertus, E. Scrocco, and J. Tomasi, Chem. Phys. 55 (1), 117-129 (1981).

[35] P.J. O'Malley, J. Phys. Chem. A 101 (35), 6334-6338 (1997).

[36] S. Sinnecker, E. Reijerse, F. Neese, and W. Lubitz, J. Am. Chem. Soc. 126 (10), 3280-3290 (2004).

[37] D.M. Chipman, J. Phys. Chem. A 104 (50), 11816-11821 (2000).

[38] L.A. Eriksson, F. Himo, P.E.M. Siegbahn, and G.T. Babcock, J. Phys. Chem. A 101 (49), 9496-9504 (1997).

[39] H. Musso, in Oxidative Coupling of Phenols, edited by W.I. Taylor and A.R. Battersby (Marcel Dekker Inc., New York, 1967).

[40] M. Uchimiya and A.T. Stone, Chemosphere 77 (4), 451458 (2009). 